\title{
Private Altersvorsorge: Betriebsrentenrecht und individuelle Vorsorge
}

\author{
Eine rechtsvergleichende Gesamtschau
}

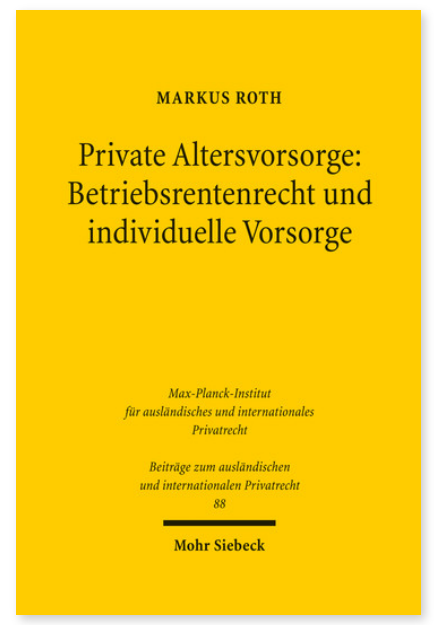

2009. LIV, 746 Seiten. BtrIPR 88

ISBN 978-3-16-151081-6

DOI 10.1628/978-3-16-151081-6

eBook PDF 129,00€
Der demographische Wandel und die Strukturprobleme der gesetzlichen Rentenversicherung legen eine Stärkung der privaten Altersvorsorge nahe. Eine rechtsvergleichend fundierte Aufarbeitung des deutschen Rechts fehlt bislang. Markus Roth schließt diese Lücke mit einer Gesamtschau des Rechts der individuellen Altersvorsorge sowie des Betriebsrentenrechts. Aufbauend auf den Rechtsinstituten privater Vorsorge arbeitet er allgemeine Schutzprinzipien heraus. Dabei bilden Garantien, Vertragsbeendigung und Mitsprache ein vorsorgerechtliches Schutzdreieck, das insbesondere durch Informationspflichten und das Leitbild eines treuepflichtig verwalteten Sondervermögens ausgeformt wird. Angewendet und konkretisiert werden die Schutzprinzipien privater Vorsorge bei der Darstellung des Altersvorsorgevertrags von seinem Abschluss bis zur Auszahlungsphase.

Die Gesamtschau des Betriebsrentenrechts und der individuellen Vorsorge zeichnet die Entwicklung des Rechts der privaten Vorsorge nach und bezieht interdisziplinär behavioral economics sowie rechtsvergleichend insbesondere die USA, das Vereinigte Königreich und die Schweiz mit ein. Behandelt werden in diesem Zusammenhang neben dem Betriebsrentenrecht das Versicherungs-, und Investmentrecht, aber auch trust und Treuhand: contractual trust arrangements spielen im deutschen Betriebsrentenrecht bereits heute eine herausragende Rolle. Mit dieser Untersuchung legt der Autor die dogmatischen Grundlagen für die reine Beitragszusage. Er stellt die Informationspflichten der Institutionen privater Vorsorge auf eine gemeinsame Grundlage und entwickelt sie weiter.

Markus Roth Geboren 1968; Studium der Rechtswissenschaft in Konstanz; 2000 Promotion; seit November 2002 wissenschaftlicher Referent am Max-Planck-Institut für ausländisches und internationales Privatrecht.

Jetzt bestellen:

https://mohrsiebeck.com/buch/private-altersvorsorge-betriebsrentenrecht-und-individuelle-vorsorge-9783161510816? no_cache=1

order@mohrsiebeck.com

Telefon: +49 (0)7071-923-17

Telefax: +49(0)7071-51104 